\title{
Visual impact from quarrying activities: a case study for planning the residential development of surrounding areas
}

\author{
G. Alfaro Degan, D. Lippiello, L. Picciolo \& M. Pinzari \\ Department of Engineering, ROMA TRE University, Italy
}

\begin{abstract}
Quarrying activities and rock extraction generally cause several environmental effects on the surrounding areas. The alteration of landscape due to activities like excavation, drilling or blasting, in particular, often generates a visual impact on the receptors set in the surroundings. Among these effects, the shape, extent, or chromatic contrast of the mining surface with the original land form may represent a huge loss of appeal for the growth of new urban settlements. To eliminate, or if not possible, at least to reduce these effects, two different approaches may be developed. The first, based on the reclamation of the post mined quarry surface is aimed at restoring the ecological balance taking into account geological parameters but also local flora and climate. It may be effective however it requires many years to be developed and above all it implies rock extraction to be suspended.

On the other hand the way of prevention is based on the assessment of visual impact when the quarry plant is to be set or when receptor location is to be settled.

The contents of this paper are focused on the results of a case study developed in the northern area of Rome in which the existence of a grey dark basalt quarry represented the opportunity to test this preventive approach: in the surroundings of the quarry plant some contractors aimed to build a residential area and a preliminary scheme was in progress. So, in the first part, the two most important visual assessment methods such as that defined by the EC decision 272/02 and the $\mathrm{L}_{\mathrm{vi}}$ (Level of Visual Impact) are performed and compared. Some scenarios are studied by varying not only the receptor location but the quarry exploitation method too. Then, with regard to the threshold limit values and quality classes defined in the $\mathrm{EC}$ decision, the construction of $\mathrm{L}_{\mathrm{vi}}$ maps is performed by means
\end{abstract}


of geostatistical Ordinary Kriging. This technique allows, as for the presented case study, to identify the best output configuration of future settlements taking into account not only the current configuration but also the development of the quarry itself and its spatial expansion.

The residential area is now under construction.

Keywords: visual impact assessment, quarry, landscape alteration, geostatistics, Ordinary Kriging.

\section{Introduction}

Landscape alteration and its influence on visual impact of viewers is only one of the effects quarrying activities may generate on surrounding receptors. Moreover, as for its characteristics, it represents one of the most critical nuisances. In fact, first of all, the sustainability of any reclamation scheme aimed to eliminate, or if not possible, to reduce its effects, imply a long term planning and design. Secondly, any appropriate methodology for planning reclamation should imply a complex evaluation of many features such as landscape alteration due to quarry expansion [1,2] and exploitation methods [3]. Although the assessment itself represents a decisional tool to identify ecological criteria and requirements $[4,5]$, and plan any reclamation measure $[6,7]$, it is, indeed, often regarded as a subjective process [8], and it must be compared with the different perception and subjective taste of the observer.

However, the first phase of assessment must rely on objective reasoning and this investigation is carried out with the aim of ensuring the assessment itself may be undertaken in a systematic way making the whole procedure as objective as possible using quantitative approach.

Then, once the alteration is assessed, aesthetic perception of landscape change may be evaluated in a subjective way considering preferences expressed by different observers.

In this paper the first phase is presented.

\section{Materials and methods}

\subsection{Site description and exploitation method}

The case study presented in the paper takes place in the Northern area of Rome, in the locality of "Valle Cento" to the south of Monterosi and Nepi.

The quarrying area is on the western side of a hill characterized by a maximum altitude of about 260 meters above sea level. It is bounded on the south and east by two river systems: the "Fosso di Valle Cento" and the "Fosso di Monte Pogliano" whose confluence is about 200 meters above sea level.

Moreover, it is bordered to the south west with the Regional Natural Park of Bracciano and is located less than $3 \mathrm{~km}$ from Bracciano Lake and $1.5 \mathrm{~km}$ from the Cassia highway through which it is connected with some unpaved roads. 
All around the hill of Monte Pogliano it is under investigation the hypothesis of planning a civil area including sensitive receptors and settlements (e.g. residential buildings, shopping center, etc.).

The map of both quarry site and adjacent property is shown in fig. 1.

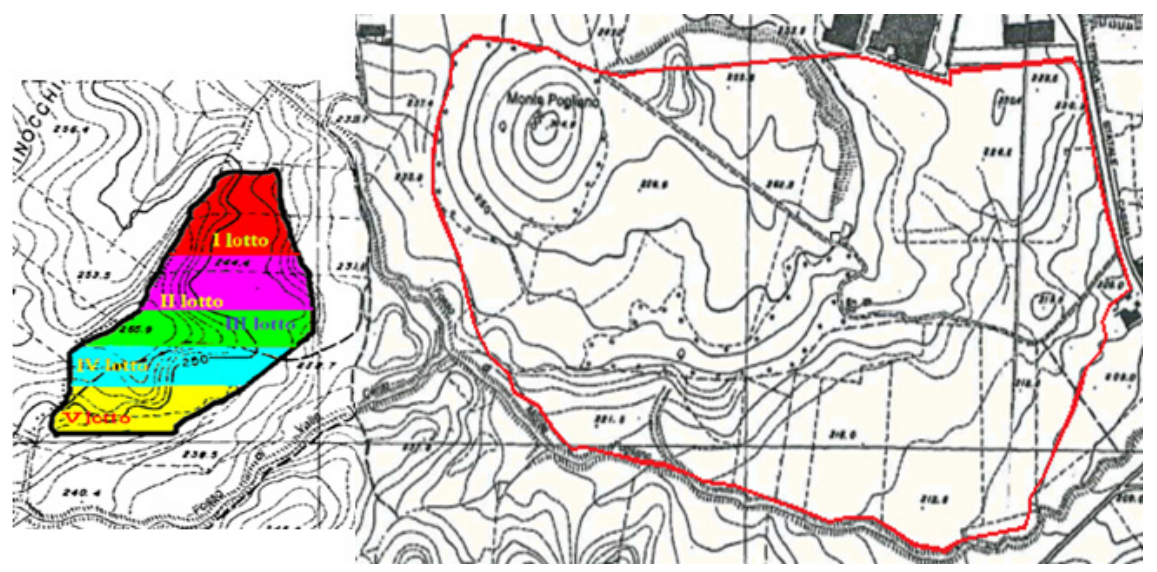

Figure 1: On the left the quarrying area divided into 5 lots, on the right, marked in red, the building area.

Mining activity has been active since the 1990s. The quarrying area includes 16 ha of which 15 represent the extractive site divided into 5 lots of 3 ha each: the extraction can be alternatively carried on concurrently on all 5 lots or in sequence.

The stone extracted is basalt, an effusive rock of volcanic origin, which is used for many applications including the production of railway ballast.

The average daily production is $817 \mathrm{~m}^{3}$ for a total annual average of $115,500 \mathrm{~m}^{3}$.

The exploitation method is that of the single level splitting: the layer is divided into a number of levels depending on the thickness of the layer itself (two of about 10 meters each in this case). Each level is divided into a number of sections (eight in the selected case as shown in fig. 2) each consisting of a slice

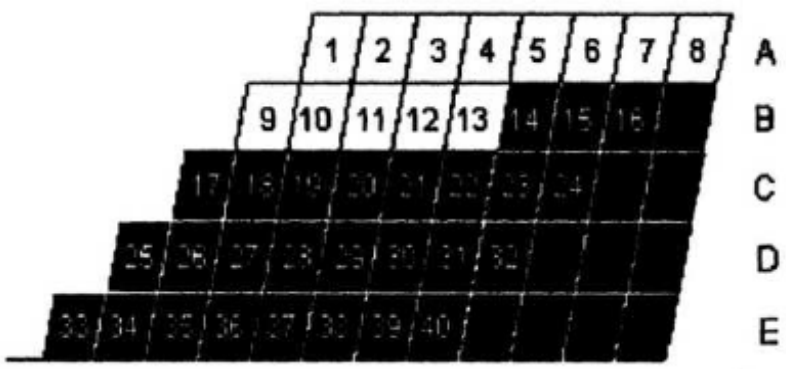

Figure 2: The exploitation method from a lateral point of view in which the first level is made up of 8 sections. 
from one side to the other one of the layer. The material is removed level by level, starting from the top of the layer. Once material is removed from the first level, reclamation procedure may be performed while stone from second level is still being extracted.

The exploitation technology is that of blasting methods according to raw material is removed from the site. Then shot rock is loaded onto trucks and transported to the bottom part of the property through slopes and unpaved roads where it is sized by crushers set in the mechanical plant itself.

\subsection{Assessment methods}

Among different visual impact assessment methods two different methodologies are presented and compared. First of all the EC decision 272/02 (Commission Decision, 2002) that establishes ecological criteria for the award of the Community eco-label for hard floor-coverings is considered, taking into account the visual impact indicator $\mathrm{x}$. It is defined to assess visual and landscape impact arising from the extractive activities of raw materials (marble, granite or others). Secondly the visual impact indicator $\mathrm{L}_{\mathrm{vi}}$, proposed by Massacci and Dentoni [9], is assessed.

These two methods are briefly summarized as follows.

According to the EC decision, the visual impact indicator $\mathrm{x}$ of the quarry is calculated by selecting a number of $\mathrm{P}$ receptors from where the following relationship is developed:

where:

$$
X \%=\frac{h^{2}}{(L \tan 30)^{2}} 100
$$

$\mathrm{h}$ is the vertical height of altered area visible from $\mathrm{P}[\mathrm{m}]$;

$\mathrm{L}$ is the horizontal distance between $\mathrm{P}$ and the altered area $[\mathrm{m}]$;

$\tan 30^{\circ}$ is the tangent of the average angle of the vision cone of the human eye; $\mathrm{x}$ is the visual impact indicator [\%].

The term $\mathrm{h}^{2}$ approximates the base surface of the visibility cone within which the compromised area can be seen, while the term $\left(\mathrm{L} \tan 30^{\circ}\right)^{2}$ approximates the base area of the average visual cone of the human eye (as shown in fig. 3 ).

In some cases (where the extension of the groove is consistent) the term in the numerator can be replaced by the product between the height and the extension of the quarry.

In this work the extension of the quarry was considered, so the modified formula was applied.

Finally, the assessed value may be weighed according with some correction factors taking into account the environmental sensitivity of the site.

In Table 1 the relationship between the $\mathrm{X}$ indicator and visual impact classes is shown.

Massacci and Dentoni [9], Bishop [10] and Pinto et al. [11] noticed that this method does not consider two essential aspects of landscape alteration: the extent of the quarry site and the chromatic contrast between the colour of the excavated material and the chromatic characteristics of the surrounding area. To assess, in a quantitative way, these two features, an alternative method was tested. 


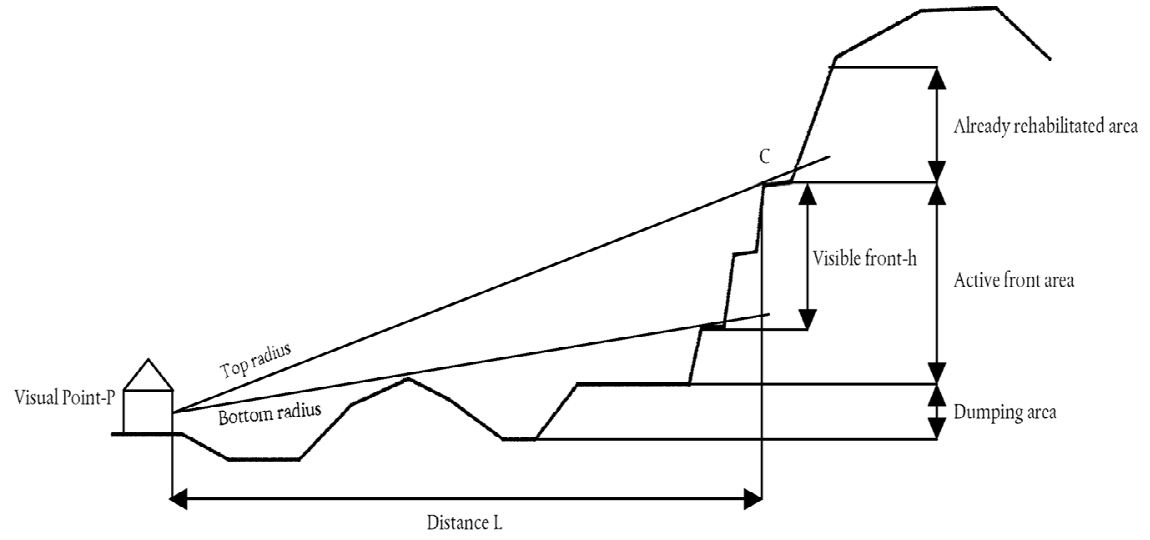

Figure 3: $\quad$ Visual impact parameters.

Table 1: $\quad$ Visual impact scores.

\begin{tabular}{ccccc}
\hline Visual impact & Excellent & Good & Sufficient & Exclusion hurdle \\
\hline Indicator & $0-10$ & $10-20$ & $20-30$ & $>30$ \\
\hline
\end{tabular}

With regard with the CIE Lab system the contrast perceived between two colours may be measured as a Euclidean distance. In fact, in the CIE Lab colour space each point is referred to as the combination of three coordinates and identifies a colour. These three parameters are $a, b$, and L: $a$ and $b$ are chromaticity coordinates while $\mathrm{L}$ is an expression of colour brightness.

For each view point, in this case represented by a picture, a single visual impact indicator $\mathrm{L}_{\mathrm{vi}}$ is calculated as follows:

$$
L_{v i}=10 \log \left(\frac{\Delta E_{\mu}}{\Delta E_{B W}} \times \frac{\Omega_{V}}{\Omega_{0}}\right)
$$

where:

$\Omega_{v}$ is solid angle within which the altered area can be seen from the view point. $\Omega_{\mathbf{o}}=8.46 \times 10^{-8}[\mathrm{sr}]$ is visibility threshold under maximum contrast conditions in a black and white space.

$\Delta \mathrm{E} \mu$ is the average value of chromatic contrast between the excavated rock and surrounding landscape.

$\Delta \mathrm{E}_{\mathrm{BW}}$ is Euclidean distance between black and white. The value of $\Delta \mathrm{E}_{\mathrm{BW}}$ is 100 in CIE Lab colour space, as the chromatic coordinates of black and white are respectively $(L=0 ; a=0 ; b=0)$ and $(L=100 ; a=0 ; b=0)$.

When the ratio between $\Delta \mathrm{E} \mu$ and $\Delta \mathrm{E}_{\mathrm{BW}}$ is equal to 1 , it implies the condition of maximum chromatic contrast and the $\mathrm{L}_{\mathrm{vi}}$ is noted as $\mathrm{L}_{\mathrm{v}}$

The comparison between $\mathrm{x}$ parameter and $\mathrm{L}_{\mathrm{v}}$ under maximum chromatic contrast conditions allows us to identify the corresponding quality classes set by EC decision and expressed in $\mathrm{dB}$. 
Table 2: $\quad$ Correlation between x parameter and Lvi indicator.

\begin{tabular}{|c|c|c|c|}
\hline $\mathrm{X}[\%]$ & $\varphi=\theta[\mathrm{rad}]$ & $\Omega_{\mathrm{V}}[\mathrm{sr}]$ & $\mathrm{L}_{\mathrm{vi}}[\mathrm{dB}]$ \\
\hline 10 & 0.033 & 0.0011 & 41.0 \\
\hline 20 & 0.064 & 0.041 & 46.8 \\
\hline 30 & 0.094 & 0.088 & 50.2 \\
\hline
\end{tabular}

\section{Results}

\subsection{Output values and data comparison}

Visual impact assessment was performed in 15 observation points set all over the building area. These points were selected to best represent the visual impact level at each location and its spatial variability all around the investigated area. So taking into account altitude levels they were dislocated on to an irregular grid shown in figure 4.

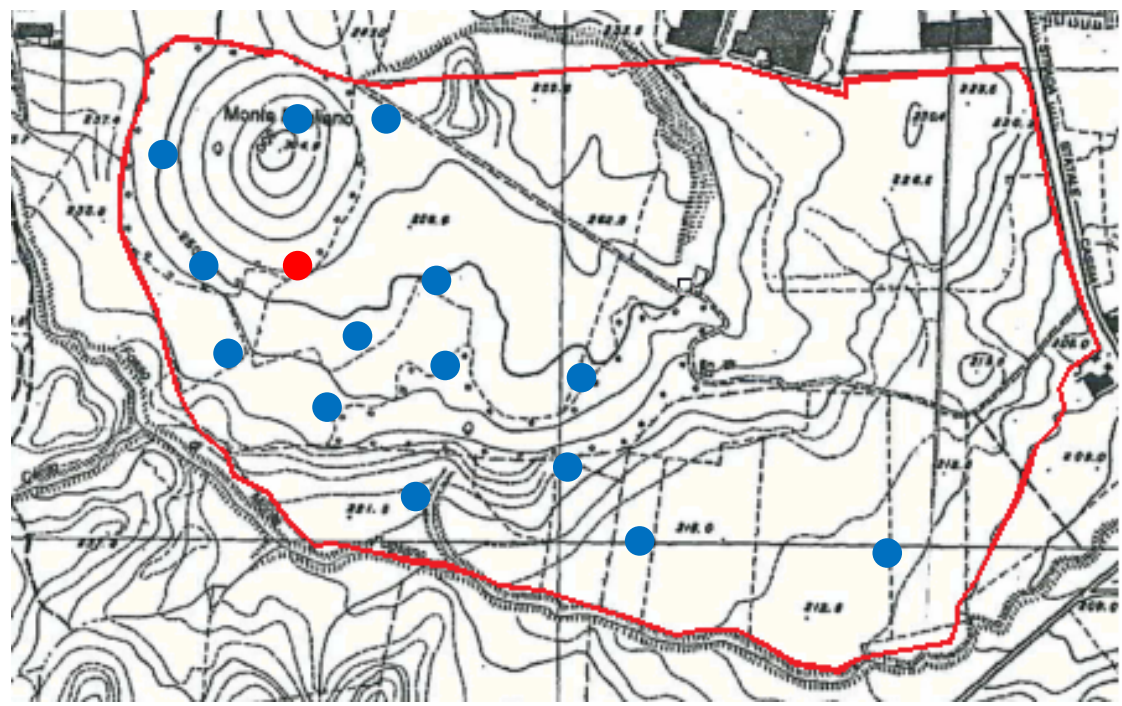

Figure 4: Observation points (in blue) selected in the building area.

In order to characterize the quarry expansion $[12,13]$, the assessment was carried out both in the case of simultaneous cultivation of all 5 lots and in the case of single lot exploitation. So 6 different indexes were carried out at each observation point.

In table 3 the results, referred to an observation point (the red one in fig. 4) are summarized. The last line of the table is referred to as the contemporary cultivation of all five lots. 
Table 3: $\quad$ Visual impact levels for a single receptor.

\begin{tabular}{|c|c|c|c|c|c|}
\hline Lot $\mathrm{n}^{\circ}$ & $x[\%]$ & $\Omega_{\mathrm{V}}[\mathrm{sr}]$ & $\mathrm{L}_{\mathrm{v}}[\mathrm{dB}]$ & $\Delta \mathrm{E} \mu / 100$ & $\mathrm{~L}_{\mathrm{vi}}$ \\
\hline 1 & 5,1 & 0,0138 & 52,1 & 0,495 & 50,0 \\
\hline 2 & 4,9 & 0,0118 & 51,4 & 0,495 & 48,4 \\
\hline 3 & 1,8 & 0,0060 & 48,5 & 0,495 & 45,5 \\
\hline 4 & 1,3 & 0,0032 & 45,7 & 0,495 & 42,7 \\
\hline 5 & 0,8 & 0,0025 & 44,7 & 0,495 & 41,7 \\
\hline $\mathrm{C}$ & 1,6 & 0,0140 & 52,2 & 0,495 & 50,0 \\
\hline
\end{tabular}

For each source receptor configuration, two cases are considered: the first whose indicator is referred to as $\mathrm{L}_{\mathrm{v}}$, in which chromatic contrast is considered maximum between black and white, is in the fourth column of table 2 . The second parameter, $\mathrm{L}_{\mathrm{vi}}$, in the last column of the same table, is assessed including the chromatic contrast parameter.

By comparing output results for each observation point, it has been noticed that the worst case as for visual impact was that of simultaneous extraction of stone from all 5 lots as the extent of quarried area increased hugely.

In the following table the results from this case are presented.

Table 4: $\quad$ Simultaneous cultivation of all lots: visual impact levels.

\begin{tabular}{|l|l|l|l|l|l|}
\hline $\begin{array}{l}\text { Point of } \\
\text { view }\end{array}$ & $\begin{array}{l}\text { Distance } \\
{[\mathrm{Km}]}\end{array}$ & $\Omega_{\mathrm{V}}[\mathrm{sr}]$ & $\mathrm{Lv}[\mathrm{dB}]$ & $\Delta \mathrm{E} \mu / 100$ & Lvi $[\mathrm{dB}]$ \\
\hline 1 & 0,55 & 0,0044 & 47,1 & 0,367 & 42,8 \\
\hline 2 & 1,0 & - & - & - & - \\
\hline 3 & 0,30 & 0,0540 & 58,1 & 0,517 & 55,1 \\
\hline 4 & 0,40 & 0,0140 & 52,2 & 0,495 & 52,2 \\
\hline 5 & 0,45 & 0,0084 & 49,9 & 0,355 & 45,4 \\
\hline 6 & 0,55 & - & - & - & - \\
\hline 7 & 0,6 & - & - & - & - \\
\hline 8 & 0,55 & 0,0039 & 46,1 & 0,294 & 41,3 \\
\hline 9 & 0,70 & 0,00168 & 42,9 & 0,315 & 37,9 \\
\hline 10 & 0,65 & 0,00190 & 43,5 & 0,295 & 38,2 \\
\hline 11 & 0,45 & 0,0079 & 49,7 & 0,342 & 45,0 \\
\hline 12 & 0,55 & 0,0041 & 46,8 & 0,362 & 42,4 \\
\hline 13 & 0,35 & 0,0592 & 58,4 & 0,436 & 54,8 \\
\hline 14 & 0,35 & 0,0648 & 58,8 & 0,527 & 56,0 \\
\hline 15 & 0,75 & 0,00087 & 40,1 & 0,515 & 37,2 \\
\hline
\end{tabular}

\subsection{Geostatistical estimation of $\mathrm{L}_{v}$ indicators: Ordinary Kriging}

Once the parameters were calculated, the final step was that of defining a contour map of iso $\mathrm{L}_{\mathrm{Vi}}$ levels in order to immediately allow a clear identification of corresponding value at each location. 
The geostatistical approach seemed to represent a useful tool according to which analysing and interpolating spatial data [14].

A regionalized variable $\Psi$ was defined as follows:

$$
\psi=\frac{\Delta E_{\mu}}{\Delta E_{B W}} \times \frac{\Omega_{V}}{\Omega_{0}}
$$

in which symbols maintain the definition given in (2).

The introduction of this variable $(\Psi)$ is due to the characteristics of Ordinary Kriging method based on a linear interpolation of values that cannot be performed with logarithmic function. Once the estimation is carried out, the conversion to visual level expressed in $\mathrm{dB}$ is performed.

To obtain a continuous map of the visual level, instead of calculating the parameter at each receptor it was convenient to consider visual impact level as a random function having a given spatial structure, or in other word, having a given spatial correlation, which can be described using appropriate statistical quantities. As for this case, this variable is the so called regionalized variable defined in (3).

The study of regionalized variables starts from the ability to interpolate a given field starting from a limited number of available values, but preserving the theoretical spatial correlation. This is accomplished by means of a technique called Kriging and largely applied in earth science disciplines for the spatial interpolation of various physical quantities given a number of spatially distributed measurements.

The OK (Ordinary Kriging) estimator is a linear estimator that matches the correct expected value of the population (available values) and minimizes estimation variance

A map of the estimated regionalized variable, and possibly its confidence intervals, can be obtained by defining a grid and solving the linear system for each point in the grid.

Each unknown value is estimated as a linear combination of parameter at known points as follows:

$$
\Psi\left(X_{0}\right)=\sum_{i=1}^{N} \lambda_{i} \Psi\left(X_{i}\right) \pm 2 \sigma_{0}
$$

where:

$\Psi\left(X_{0}\right)$ is the estimated value of regionalized variable

$\Psi\left(X_{i}\right)$ is the known value of regionalized variable at each of the $\mathrm{N}$ selected locations

$\lambda_{i}$ is weighting factor at each selected location

$\sigma_{0}$ is the value of estimation variance

Once, the regionalized variable is defined, its variogram is calculated and fitted as a function constituted of a nugget effect and a spherical function.

Then final estimation is assessed on a regular grid solving Kriging system. The last step is the conversion of $\Psi$ parameter to the logarithmic function: the 
result is represented in the map shown in the following figure where the trend of these curves may be appreciated.

Among the 6 maps corresponding to the different source configuration (quarry exploitation methods), the following one is that referred to as the most critical case in which the simultaneous cultivation of all 5 lots implies the highest value of $L_{v}$ values obtained under the condition of maximum chromatic contrast.

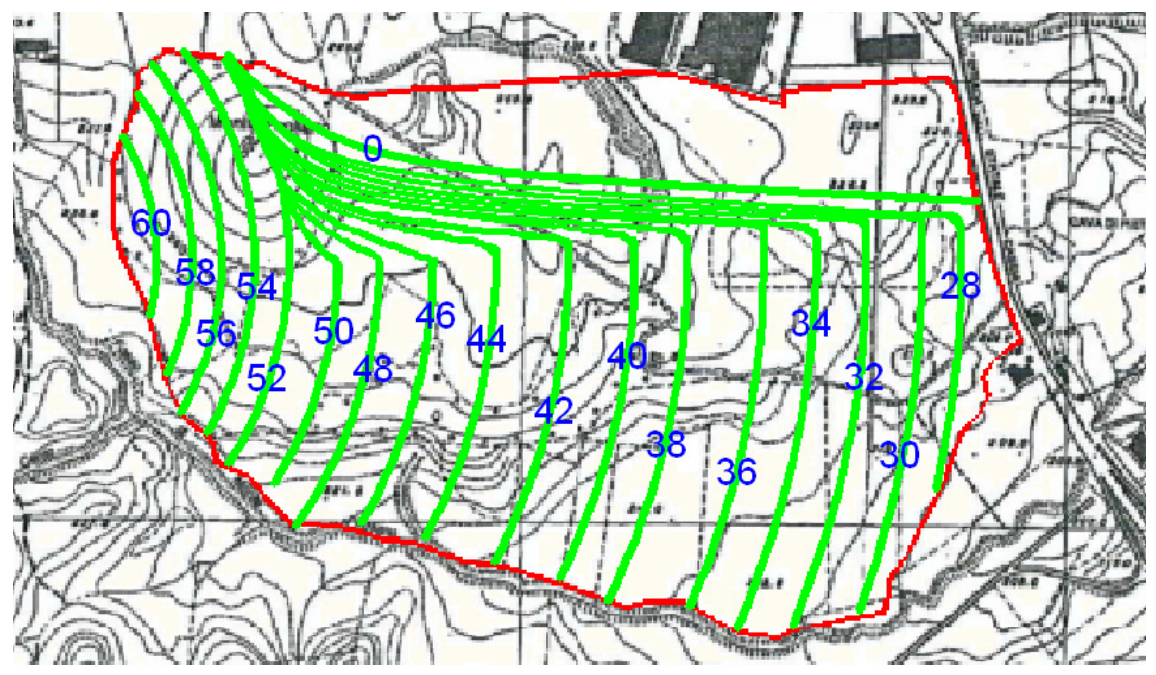

Figure 5: $\quad$ Iso $\mathrm{L}_{\mathrm{v}}$ contour map.

To test the quality of the output map, the comparison between estimated values and assessed ones is carried out and presented in fig. 6 .

\section{Discussion and conclusion}

By comparing estimated values and assessed ones it is possible to appreciate a good correlation with two exceptions: in two of the selected points from where the quarry is not visible and the visual impact indicator is null, the Kriging system returns respectively 13 and $22 \mathrm{~dB}$.

This result may be explained considering Kriging as the result of theoretical spatial correlation and if some external events influence this variability (e.g. trees or obstacles between source and receptor) the estimator does not include its effects. This feature, mixed to the variability of altitude seems to reasonably explain these differences.

Future developments of this study could be addressed towards two directions.

The first is connected with the visual assessment method that, as shown, is based on the extent of the industrial site and the colour contrast with the surrounding environment. A further step may be that of including a parameter connected with shape contrast of industrial site with the landscape, or, in other words, assessing if industrial site is notable by difference in physical shape 


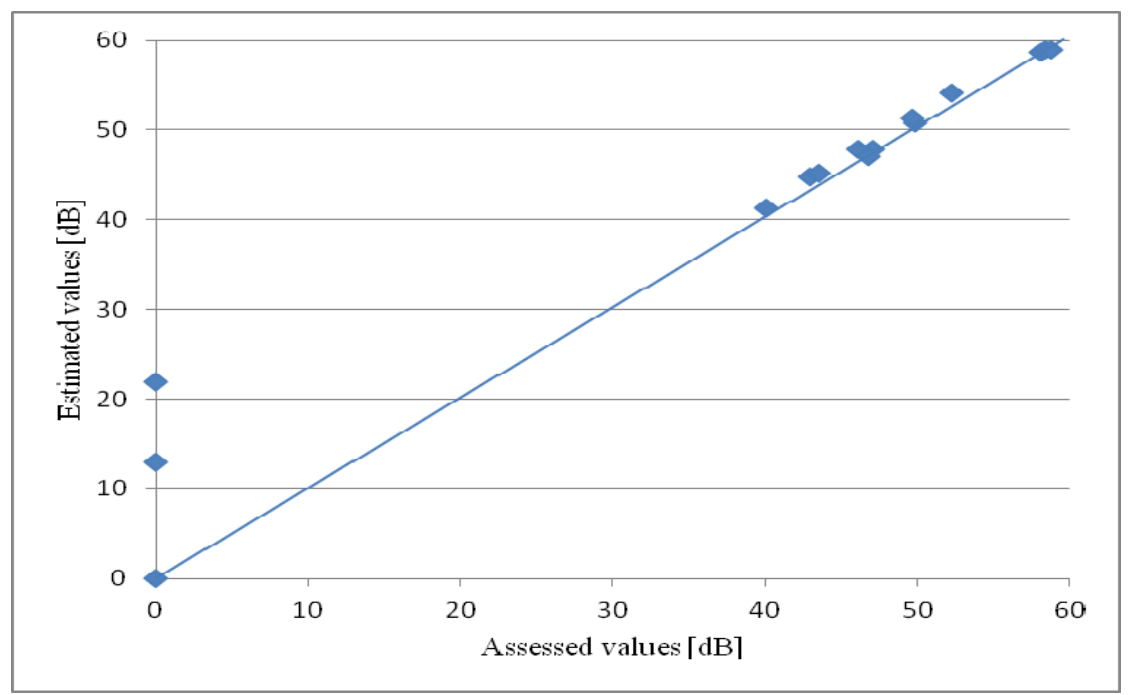

Figure 6: Comparison between estimated values and assessed ones.

compared to other things on the landscape (e.g. presence of existing man made elements in the view).

The second one is connected with geostatistical approach: generally the experimental variogram and so the estimation, is most accurate for small distances between assessed values, with uncertainties growing rapidly when distance is large. The influence of these characteristics, here represented by obstacles, screens, trees or others, may be decreased by using moving neighborhoods. With this variant, now being tested, only the points that lie within a prefixed radius contribute to the estimation of surrounding values.

In conclusion, although estimated map is affected with some errors due to local characteristics, the geostatistical approach seems to represent a useful tool in the phase of visual impact assessment and planning new settlements.

\section{References}

[1] Mouflis G.D., et al. Assessment of the visual impact of marble quarry expansion (1984-2000) on the landscape of Thasos Island, NE Greece. Landscape and Urban Planning 86 (1), pp. 92-102, 2008.

[2] Menegaki M.E., Kaliampakos D.C. Landscape analysis as a tool for surface mining design. Environment and planning B: Planning and Design 33 (2), pp. 185-196.

[3] Alfaro Degan G, Lippiello D, Pinzari M., Rullo S. Ricognizione sui metodi di coltivazione delle cave per splateamento. Geologia dell'Ambiente, 3 pp. 3-7, 2011. 
[4] Commission Decision 2002/272/EC of 25 March 2002 establishing the ecological criteria for the award of the Community eco-label to hard floorcoverings. OJ No L 94:13-27, 11.04. 2002.

[5] Commission Decision 2009/607/EC of 9 March 2009 establishing the ecological criteria for the award of the Community eco-label to hard coverings. OJ No L 208:21-38 12.08, 2009.

[6] Panagopoulos T., Matias R., Ramos B.R. Visual impact and reclamation of limestone quarries in Algarve Portugal. Proceedings of the 24th National Meetings of the American Society of Mining and Reclamation, pp. 176-182, 2007.

[7] Jordan M.M. et al. Geological and environmental implications in the reclamation of limestone quarries in Sierra de Callosa (Alicante Spain). Env. Earth Science 59 (3), pp. 687-694.

[8] Panagopoulos T., Ramos B. Aesthetic and visual impact assessment of a quarry expansion Proceedings of the 2006 IASME/WSEAS Int. Conf. on Energy, Environment, Ecosystems \& Sustainable Development, Greece, pp. 378-381, 2006.

[9] Massacci G, Dentoni V. Assessment of visual impact induced by surface mining with reference to a case study located in Sardinia (Italy), Env Earth Science, 68, pp. 1485-1493, 2013.

[10] Bishop I.D. Assessment of visual qualities, impacts, behaviours, in the landscape, by using measures of visibility. Environ Plann B: Plan Des 30:677-688, 2003.

[11] Pinto V, Font S, Salgot M, Tapias J, Mañá T. Image analysis applied to quantitative evaluation of chromatic impact generated by open-pit quarries and mines. Environ Geol 41, pp. 495-503, 2002.

[12] Ayuga F, Garcia L, Hernandez J. Assessment of the visual impact made on the landscape by new buildings: a methodology for site selection. Lanscape and Urban Planning 68 (1), pp. 15-28, 2004.

[13] Kumar Dey P, Ramcharan E. Analytic hierarchy process helps select site for limestone quarry expansion in Barbados. Journal of Environmental Management 88 (4), pp. 1384-1395, 2008.

[14] Alfaro Degan G, Lippiello D, Pinzari M. A geostatistical approach to the functional analysis space technique: a case of study. Advances in Safety and Reliability - Proceedings of $16^{\text {th }}$ European Safety and Reliability Conference (ESREL). Ed: Kolowrocki K, Taylor \& Francis, Vol. 1, pp. 45-52, 2005. 